\title{
The seascape nursery: a novel spatial approach to identify and manage nurseries for coastal marine fauna
}

\author{
Authors: Ivan Nagelkerken ${ }^{1}$, Marcus Sheaves ${ }^{2}$, Ronald Baker ${ }^{2,3}$, \& Rod M Connolly ${ }^{4}$ \\ ${ }^{1}$ Southern Seas Ecology Laboratories, School of Earth and Environmental Sciences, DX 650 \\ 418, The University of Adelaide, Adelaide, SA 5005, Australia; ${ }^{2}$ School of Marine and \\ Tropical Biology, James Cook University, Townsville, Qld 4811, Australia; ${ }^{3}$ CSIRO Land \\ and Water, Townsville, Qld 4811, ${ }^{4}$ School of Environment \& Australian Rivers Institute \\ (ARI) - Coast \& Estuaries, Griffith University, Gold Coast campus, Qld 4222, Australia \\ Correspondence: Ivan Nagelkerken, School of Earth and Environmental Sciences, DX 650 \\ 418, The University of Adelaide, Adelaide, SA 5005, Australia. Tel: (61) 8 83134137. E- \\ mail: ivan.nagelkerken@adelaide.edu.au
}

Keywords Ecosystem connectivity, juvenile fauna, mangrove, ontogenetic migration, salt marsh, seagrass

\begin{abstract}
Coastal marine and estuarine ecosystems are highly productive and serve a nursery function for important fisheries species. They also suffer some of the highest rates of degradation from human impacts of any ecosystems. Identifying and valuing nursery habitats is a critical part of their conservation, but current assessment practices typically take a static approach by considering habitats as individual and homogeneous entities. Here we review current definitions of nursery habitat and propose a novel approach for assigning nursery areas for mobile fauna that incorporates critical ecological habitat linkages. We introduce the term 'seascape nurseries' which conceptualizes a nursery as a spatially-explicit seascape consisting of multiple mosaics of habitat patches that are functionally connected. Hotspots of animal abundances/productivity identify the core area of a habitat mosaic, which is spatially constrained by the home ranges of its occupants. Migration pathways connecting such hotspots at larger spatial and temporal scales, through ontogenetic habitat shifts or inshoreoffshore migrations, should be identified and incorporated. The proposed approach provides a realistic step forward in the identification and management of critical coastal areas, especially in situations where large habitat units or entire water bodies cannot be protected as a whole due to socio-economic, practical, or other considerations.
\end{abstract}




\section{Introduction}

Coastal ecosystems provide a range of valuable ecosystem services, such as fisheries production, protection against coastline erosion, and carbon sequestration (Costanza et al. 1997). With about $60 \%$ of the world's population living within $100 \mathrm{~km}$ of the coastline (Vitousek et al. 1997) these ecosystems have suffered from rapid degradation (Waycott et al. 2009). Coastal and estuarine systems are highly productive and important for food security and livelihoods. Where multiple ecosystems are hydrologically and ecologically connected, a key function is the replenishment of offshore populations of commercially and ecologically important species of fish and crustaceans (Beck et al. 2001). The nursery function of these systems has received much attention over the last decade but current procedures for identifying and evaluating critical habitats lag our scientific understanding of processes that drive nursery function and productivity. In this perspective we propose a novel approach for delineating nursery areas for mobile fauna, incorporating ecological habitat linkages resulting from animal movements that occur at different spatial and temporal scales.

Three lines of research tackle the issue of coastal ecosystem connectivity for marine fauna, but at different conceptual scales. Firstly, the nursery-role hypothesis is mainly focused on identifying the nursery habitats that contribute most to offshore adult populations (Beck et al. 2001; Nagelkerken 2009). Secondly, ecosystem-connectivity studies have largely attempted to correlate a variety of structural metrics of coastal nursery habitats to catches of offshore fishery stocks (Manson et al. 2005). Finally, seascape studies have applied techniques and concepts from landscape ecology to understand what drives the spatial patterning of animal communities in coastal nursery habitats (Sheaves and Johnston 2008; Boström et al. 2011). While each of these research directions has received increasing attention in the last decade or two, lack of integration between them has led to gaps in the development of appropriate conservation and management strategies.

The nursery-role and ecosystem-connectivity approaches typically consider critical habitats as individual, homogeneous entities. This potentially forces managers faced with conflicting objectives for conservation and alternative uses to evaluate and then trade off entire habitats against one another when determining priorities (Weinstein 2008). Moreover, protected areas with fixed boundaries are ineffective in protecting moving or transient species (Rayfield et al. 2008). The seascape-ecology approach points to a different solution, based on mosaics of habitat patches at smaller spatial scales (Simenstad et al. 2000). The spatial characteristics of habitat patches play an important role in structuring associated animal communities, but typically are not considered in assessments of nursery value, leaving a critical knowledge and conservation gap (Beck et al. 2001; Adams et al. 2006; Boström et al. 2011).

Previous attempts to define marine nurseries have provided an important, but relatively basic, framework for the identification of nursery habitats. These approaches are static in that they do not indicate how to specifically incorporate dynamic processes, such as ontogenetic habitat shifts, animal movement, and spatially-explicit usage of habitat patches and corridors within seascapes. This static, single-habitat approach potentially leads to incomplete or incorrect identification of critical habitats. The aim of this paper is to take a more holistic approach in identifying nurseries. We view a nursery as a spatially-explicit seascape unit (rather than a habitat unit) consisting of functionally-connected mosaics of habitats incorporating ecological processes driven by animal behaviour, and define this as the 'seascape nursery'. 


\section{Review of nursery function definitions}

Early designations of nursery habitats simply referred to habitats with high densities of juvenile animals. Beck et al. (2001) greatly improved the definition by arguing that a nursery is a habitat contributing a higher than average biomass of juveniles per unit area to the adult population than other habitats, resulting from higher densities, higher growth, lower mortality and/or greater movement. However, this approach under-appreciates juvenile habitats that have a large surface area but low density of organisms, even though their overall contribution to the adult population might be larger. Therefore, Dahlgren et al. (2006) suggested that identification of nurseries should be based on their total contribution to the adult population. This was criticized as an approach that failed to consider the importance of dynamic processes that underpin nursery function (Sheaves et al. 2006), but no specific solutions were offered (Layman et al. 2006). While some studies (e.g. Beck et al. 2001; Adams et al. 2006) have covered important factors that regulate nursery value, no significant steps towards a more comprehensive and realistic method for the identification of nurseries have occurred. Clearly, managing a nursery habitat as a whole unit will not be effective without considering the sequence of habitats that are used throughout ontogeny, while other aspects of nursery habitats (e.g. movement corridors, density hot-spots) should be considered to conserve the most productive and important habitat patches within nursery habitats. Some of these aspects have been briefly mentioned in previous studies (Beck et al. 2001; Adams et al. 2006), but a framework of how to address these issues is still lacking. In the present study we propose a potential framework to enhance identification and conservation of nurseries.

We concur with the current view that the value of nurseries (as defined by Beck et al. 2001) relates to their ultimate contribution to the support of populations. However, we move beyond the approaches that identify nurseries as static habitat units, and provide a perspective on how advances in seascape ecology can enhance designation and valuation of nursery habitats for animals that use inshore habitats before migrating offshore ("ontogenetic shifters"; Adams et al. 2006). Like previous efforts, our goal is to improve the management and conservation of critical nursery habitats. Here we build on those efforts to gain an improved measure for nursery habitat designation that captures critical processes and habitat linkages that underpin nursery function and might otherwise be missed by earlier approaches.

\section{Early-juvenile population bottlenecks: identifying critical settlement habitats}

Searching for preferred habitat while in the water column is risky and therefore settlementstage larvae often occupy the first-encountered suitable habitat when entering estuaries or lagoons from the open ocean (Grol et al. 2011), with subsequent shifts to other habitats in a step-wise pattern (Cocheret de la Morinière et al. 2002). Less structurally complex habitats such as sand patches, macroalgal clumps or dead coral rubble may function as important settlement habitats (Dahlgren and Eggleston 2000), but are often disregarded in their value for settling larvae. The identity of transient settlement habitats is unknown for many species, they may be occupied only briefly, yet they may well form population bottlenecks for early postsettlement stages (Fodrie et al. 2009). They are easily missed because of the small sizes at which juveniles occupy these transient habitats and because of the relatively short duration of occupancy. However, many species settle from the plankton during specific seasons of the year, and field surveys should be performed during these seasons to identify important settlement areas. We specifically recommend that these often-missed first-stage habitats be considered in the seascape nursery concept. 


\section{Figure legend}

Figure 1 (a) Example as described in the text of a seascape nursery located in a clear-water, micro-tidal lagoon supporting a variety of habitat types; the seascape nursery consists of several habitat mosaics connected through diel and ontogenetic movements. (b) Example of a seascape nursery for penaeid shrimps in a turbid, meso-tidal salt marsh estuary. This specific case study refers to coastal salt marsh ecosystems of the northern Gulf of Mexico which are considered critical in the support of highly productive shrimp fisheries (Turner 1977). Adults spawn offshore and post-larvae recruit to shallow habitats in the marsh complex of coastal bays and estuaries where conditions are favourable (salinity,

temperature, food availability) (Rozas and Minello 2011). There is a staged ontogenetic progression of juveniles from the marsh complex to open bays, and subsequent migration to join adult stocks offshore (Lindner and Cook 1970). Although represented as circles for consistency of presentation, a narrow strip at the vegetation-open water interface represents a density hotspot for juvenile shrimp within the marsh complex (Minello et al. 2008). Image credits: Kate Moore, Jane Thomas, Tracey Saxby and Diana Kleine (IAN Image Library ian.umces.edu/imagelibrary) and Nina McLean (James Cook University). 
Figure 1

a)
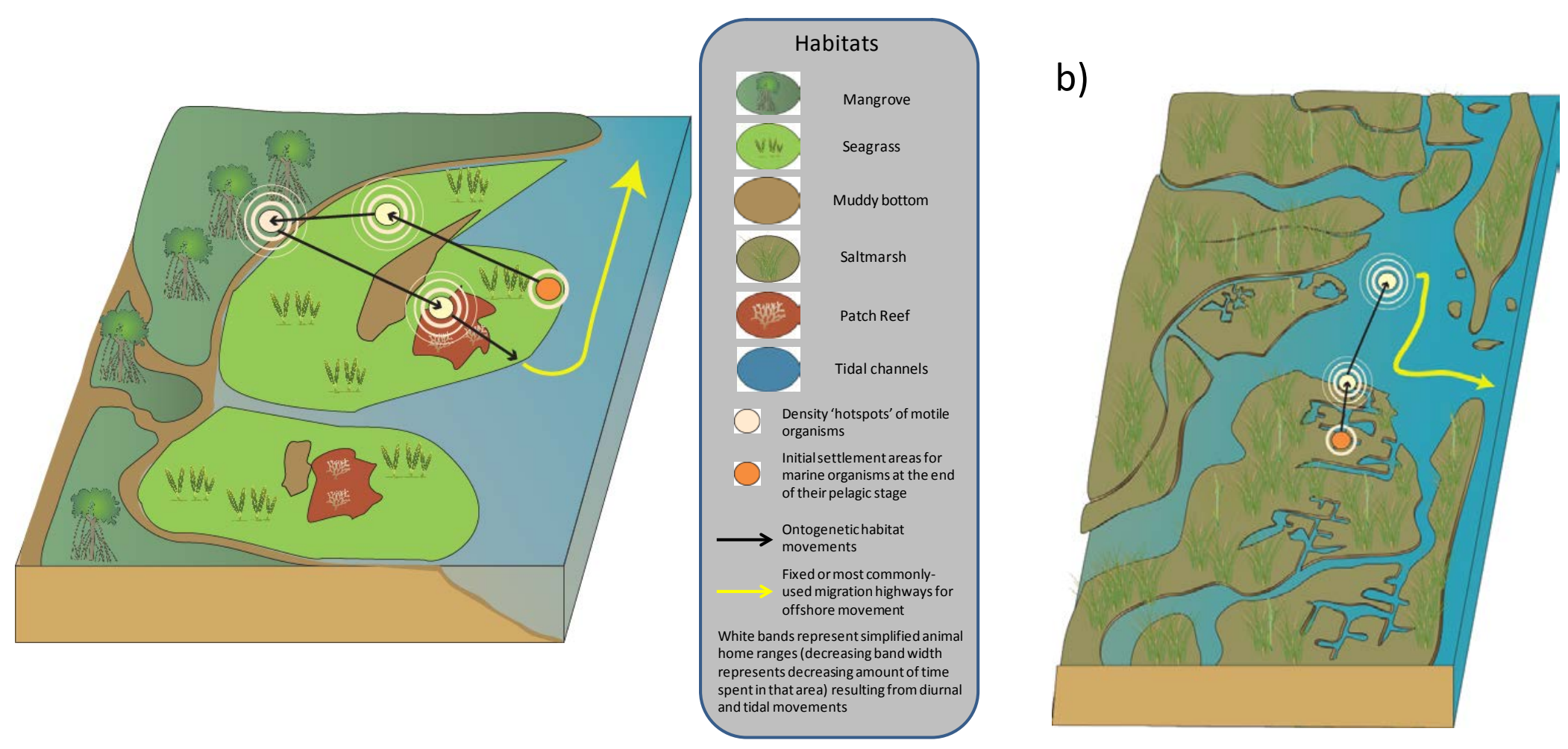


\section{Habitat connectivity: predictable diel, tidal, and ontogenetic habitat shifts}

Few species are confined to a single nursery habitat (Nagelkerken 2007). Seascape studies have shown that many animals utilize a mosaic of habitats on a daily basis (Boström et al. 2011). Mobile animals connect adjoining habitats through tidal, shelter-seeking, or foraging movements (Hammerschlag et al. 2010; Igulu et al. 2013; Olds et al. 2013; Baker et al. in press). These migrations are highly predictable in timing and routes followed (Krumme 2009), to such extent that some predators in nursery areas have adapted their behaviour to coincide with these migrations (Helfman 1986). Animals pass through non-nursery habitats on a regular basis while moving between patches of core habitat in search of food or shelter (Hitt et al. 2011). These movements usually occur within a specified home range around the core area of their shelter sites (Farmer and Ault 2011), which are often located near to structurally-complex habitats (Verweij and Nagelkerken 2007). Species often show homing behaviour to such shelter sites, which may persist over periods of weeks to months (Helfman et al. 1982). On longer time-scales, many species show ontogenetic shifts among habitats because of changing resource needs (e.g. food, shelter) as well as altered predation risk during different life stages (Dahlgren and Eggleston 2000; Kimirei et al. 2013b). Due to strong connectivity among habitat patches, assigning single nursery habitats disregards the role that earlier life-stage habitats or adjoining (feeding/shelter) habitats play in the population dynamics and ultimate stock replenishment of nursery species.

\section{The seascape mosaic: hotspots of animal abundances and productivity}

Spatially-explicit use of patches within nursery habitats typically has not been quantified in relation to nursery function. In contrast, landscape-focused studies have demonstrated consistent and predictable animal density or productivity 'hotspots' in relation to spatial position within the seascape, for example based on: 1. distance to estuary mouth (Bell et al. 1988), 2. distance to feeding areas (Pittman et al. 2007), 3. proximity to high-volume tidal channels that supply larvae (Ford et al. 2010), 4. density of creek edges within marshes (Kneib 2003), 5. presence and type of adjacent habitats (Nagelkerken et al. 2001), or 6. specific salinity regimes representative of transitional areas between rivers and estuaries (Wasserman and Strydom 2011). Furthermore, habitat transition areas are specific zones within coastal seascapes that often have greater densities of organisms than areas further from edges (Dorenbosch et al. 2005). In many cases the Beck et al. (2001) and Dahlgren et al. (2006) approaches may well identify the broad nursery habitat(s) used by a population, but miss critical mosaics of habitat patches in the seascape that underpin nursery function (Sheaves 2009).

\section{Ecosystem corridors: highways connecting nurseries to adult populations}

The last stage of nursery habitat occupancy during which organisms undertake their final migration to deeper or offshore waters to join the adult population is poorly known (Gillanders et al. 2003), but telemetry studies suggest that it can occur over short periods ranging from a few hours to days (Luo et al. 2009). Specific routes within estuaries or lagoons may act as preferred corridors that lower predation risk, span the shortest distance to reach deeper water, or facilitate tidally-enhanced movements due to specific local hydrology (Zollner and Lima 1999). Some studies have indicated the importance of continuous habitat edges (Hitt et al. 2011) or unvegetated strips within continuous seagrass beds as corridors 
(Boström et al. 2006), but extensive open shallow areas normally act as barriers for movement (Turgeon et al. 2010). In intertidal areas with extensive sand or mud flats, animals will often be funnelled to subtidal habitats through narrow tidal channels. From there on, fish move to offshore waters by navigating through corridors such as deep channels, through narrow bay mouths, or through open spaces among sand banks, islets and other types of natural barriers situated at the ocean side of river deltas, estuaries and lagoons (e.g. Verweij et al. 2007; Luo et al. 2009). Incorporation of migration corridors and their temporal usage patterns is a critical consideration for the seascape nursery concept.

\section{The seascape nursery: combining nursery-function and seascape-ecology concepts}

Existing approaches to nursery habitat evaluation tend to give more weight to final juvenile stages prior to emigration to offshore adult stocks. Linkages among habitats that affect the critical growth and survival of earlier stages therefore tend to be underplayed. We suggest that the seascape nursery approach incorporates more fully those earlier stages. The importance of our approach is demonstrated in the following example for fishes with a complex life cycle. Consider a micro-tidal seascape (Fig. 1a) where fish settle largely in first-encountered, noncore habitats like coral rubble areas along edges of tidal channels or at bay mouths, subsequently progress to seagrass beds, then switch to mangroves, and finally occupy hardbottom patch reefs or rocky areas, before moving to offshore reefs (example from Nagelkerken et al. 2000 and Grol et al. 2011). In this example, individuals are also found in other habitats, but those described above are where highest fish aggregation or production occurs. During seagrass and rubble occupancy small juveniles feed and shelter in the same habitat to reduce predation, but at larger sizes they use mangroves or patch reefs for shelter and show a diel or tidal migration to nearby seagrass beds to feed (Verweij et al. 2006). During these movements, they need to move from one feeding patch to another and pass through secondary habitats, such as algal beds and sand patches, which do not play an important role for feeding or as shelter but are part of their home range (see concentric circles in Fig. 1).

In the above example, the extensive seagrass beds provide the largest overall contribution to the adult populations (e.g. Verweij et al. 2008) and would be identified as the main nursery habitats using the Dahlgren et al. (2006) approach. In contrast, expressed as a contribution per unit area the importance of seagrass beds with large surface area would typically be lower compared to other habitats with smaller surface areas where crowding of animals occurs, like mangrove stands and coral patches. Based on the Beck et al. (2001) approach such habitats that contribute most per unit area could be designated as nursery habitats even though their overall production might not be large. This could in practice lead to a debate about whether mangroves versus seagrass beds should be managed, what proportion of their total surface area should be conserved, and which areas within the estuary or lagoon should be managed, especially in cases of high-usage or exploitation by multiple stakeholders. The seascape nursery would provide a more realistic approach to this problem by revealing that (Fig. 1): 1 . transient settlement areas should be conserved, because without these there is no recruitment to 'nursery' habitats, 2. within the seascape there are principle areas (habitat mosaics), constrained by animal home ranges, that attract higher densities of mobile organisms and which are more productive than other areas, providing a management tool to prioritize areas of conservation, 3. successive essential life-stage habitats should be conserved as impacts on one habitat affect productivity in habitats occupied during later life-stages, 4 . without conserving migration routes that connect different animal hotpots during ontogeny or that facilitate movement from nurseries to offshore populations, nurseries could experience a 
switch from acting as sources to becoming juvenile sinks. A similar example from a mesotidal salt marsh system is provided in Figure 1B.

Not all species show a complex life cycle such as described above. Nevertheless, it is a common observation for a multitude of species that tidal channels are favoured for movement through shallow areas, that animal abundances are highly correlated with spatial position within coastal habitats (e.g. driven by salinity or turbidity gradients), and that animals regularly perform diel or tidal movements (Whaley et al. 2007; Krumme 2009; Turgeon et al. 2010). So even for species with a relatively simple life cycle, in terms of habitat use, previous approaches fail to incorporate several important dynamic processes other than ontogenetic habitat shifts.

\section{Practical steps to seascape nursery analysis}

While there is no single best approach to identify the precise mosaic of habitats most essential during the juvenile stages of animals in coastal marine environments, it is crucial to recognize the importance of a mosaic of contributing habitats and their linkages. Here we outline the practical steps that can help improve on earlier approaches for identification and evaluation of nursery habitat and ultimately lead to more successful protection and management of nursery function. The order and relative importance of these steps will vary depending on specific situations.

Step 1: Following Beck et al. (2001), identify the relative contribution to adult populations of all juvenile habitats at whatever scale they can be identified, e.g. using approaches such as otolith microchemistry (Gillanders and Kingsford 1996; Verweij et al. 2008). This will typically be at a coarser scale than relevant to management objectives (e.g. whole estuary or whole habitat unit) and fail to identify linkages across the seascape. We therefore recommend subsequent work to identify the smaller-scale patches within each broad-scale nursery that contribute most to the overall population replenishment by that nursery habitat. This will likely, but not necessarily overlap with density hotspots of juvenile animals during their inactive as well as active period (e.g. Ford et al. 2010), which can be identified through field surveys. Identification of specific patches that contribute most to the overall production of a nursery habitat is more challenging, but techniques such as stable isotope analysis of muscle tissue, internal and external artificial tags, or genetic and chemical markers can provide the necessary finer-scale information (Gillanders 2009; Kimirei et al. 2013a), as well as provide an answer to how this contribution may vary over time (see e.g. Kraus and Secor 2005).

Step 2: Known (from the literature) or field-acquired (through tagging studies) home range sizes may then be projected onto the identified highest-productivity density-hotspots to establish the effective area that is used as a juvenile habitat (the habitat mosaic). The home range includes the seascape that is most used on a daily basis for activities such as sheltering and foraging. Home range sizes around hotspots of animal abundances could be considered at decreasing levels of importance (see Fig. 1). Using radii of these dimensions should prove to be a more effective way to manage nursery mosaics than a static approach of single complete habitats because it uses broader information on critical habitat use. While tagging juvenile animals is difficult and movement ranges can differ considerably among species and within habitats, home range size is often a function of body size (Kramer and Chapman 1999) and juveniles of most demersal species show high site fidelity and restrict their movements to distances of no more than a few 100s m from their preferred shelter sites (Tupper 2007; Nagelkerken et al. 2008). Home ranges are larger in cases where animals occupy macrotidal 
habitats, but also in this case fidelity has been shown to high-tide and low-tide habitat components (Dorenbosch et al. 2004; Hering et al. 2010).

Step 3: Patterns of ontogenetic habitat shifts should be identified for animals that occupy the above high-productivity hotspots, so that other habitat patches that are previously or subsequently occupied are included in the designation of effective nursery mosaic (Fig. 1). This is based on the principle that patches that contribute most to adult populations can only sustain this productivity as a result of habitat linkages through ontogeny. Approaches such as following the progression of cohorts (abundances and sizes of organisms) in multiple juvenile habitats can identify which habitats are most likely to play a key role in provisioning recruits to next life-stage habitats (e.g. Fodrie et al. 2009). A critical consideration in this is to identify primary settlement areas where early life stages occur, typically at sizes at which they have not been included in field surveys.

Step 4: Primary migration routes should be identified (e.g. using telemetry or conventional tagging) that connect animal production hotspots across different spatiotemporal scales. This includes corridors that facilitate animal movement from one habitat mosaic to another through ontogeny, as well as from the seascape nursery to offshore waters (Fig. 1). Migration highways are likely to overlap among species based on the same advantages that they provide for a suite of species, like structure-rich corridors that facilitate movement under lowered predation risk (Gilliam and Fraser 2001). In deep-water estuaries and lagoons such migration corridors might be less evident or relevant than in shallower ecosystems dominated by extensive mud or sand-flats. However, due to the geomorphology of many inshore water bodies around the world, animals still need to pass through bay mouths, openings between barrier islets, or through deeper tidal channels to reach offshore waters. As such, these areas should be given high conservation importance as they maintain connectivity among inshore and offshore ecosystems.

We have attempted to present an improved framework to identify nurseries for management purposes that we believe will provide an acceptable level of accuracy for a wide range of species in a variety of coastal marine ecosystems. Our approach does not provide a single, best solution for multi-species management, as different groups of species may occupy different combinations of habitats or different areas of estuaries and lagoons. As is the case for previous approaches of nursery identification, trade-offs need to be made in terms of which species and which areas receive most consideration in terms of conservation or management. While for some systems with few, highly abundant fishery species and just one or two habitat types, a coarse approach such as that of Dahlgren et al. (2006) and Beck et al. (2001) may provide a reasonable amount of information for management purposes, there are many other systems and a multitude of (commercial and keystone) species where such an approach is likely to fail. The seascape nursery approach adds more realism to the identification of core juvenile areas within these systems by incorporating spatio-temporal drivers of animal habitat use. The intention is to achieve a practical advance for the conservation and management of inshore coastal areas that are highly productive for coastal fisheries but also prone to high levels of competing demands and degradation through human activities. We also recommend consideration of more challenging, dynamic management approaches such as mobile protected areas that follow movements of key species across their landscape (Bull et al. 2013).

\section{Acknowledgments}

We thank Aaron Adams, Bronwyn Gillanders, and two anonymous reviewers for their constructive comments on the manuscript. The authors have no conflict of interest to declare. 


\section{References}

Adams, A.J., Dahlgren, C.P., Kellison, G.T., Kendall, M.S., Layman, C.A., Ley, J.A., Nagelkerken, I. et al. (2006) Nursery function of tropical back-reef systems. Marine Ecology Progress Series 318, 287-301.

Baker, R., Fry, B., Rozas, L.P. and Minello, T.J. (in press) Hydrodynamic regulation of salt marsh contributions to aquatic food webs. Marine Ecology Progress Series M10442.

Beck, M.W., Heck, K.L., Able, K.W., Childers, D.L., Eggleston, D.B., Gillanders, B.M., Halpern, B. et al. (2001) The identification, conservation and management of estuarine and marine nurseries for fish and invertebrates. BioScience 51, 633-641.

Bell, J.D., Steffe, A.S. and Westoby, M. (1988) Location of seagrass beds in estuaries effects on associated fish and decapods. Journal of Experimental Marine Biology and Ecology 122, 127-146.

Bull, J.W., Suttle, K.B., Singh, N.J. and Milner-Gulland, E.J. (2013) Conservation when nothing stands still: moving targets and biodiversity offsets. Frontiers in Ecology and the Environment 11, 203-210.

Boström, C., Jackson, E.L. and Simenstad, C.A. (2006) Seagrass landscapes and their effects on associated fauna: a review. Estuarine Coastal and Shelf Science 68, 383-403.

Boström, C., Pittman, S.J., Simenstad, C. and Kneib, R.T. (2011) Seascape ecology of coastal biogenic habitats: advances, gaps, and challenges. Marine Ecology Progress Series 427, 191-217.

Cocheret de la Morinière, E., Pollux, B.J.A., Nagelkerken, I. and van der Velde, G. (2002) Post-settlement life cycle migration patterns and habitat preference of coral reef fish that use seagrass and mangrove habitats as nurseries. Estuarine Coastal and Shelf Science 55, 309-321.

Costanza, R., dArge, R., deGroot, R., Farber, S., Grasso, M., Hannon, B., Limburg, K. et al. (1997) The value of the world's ecosystem services and natural capital. Nature 387, 253260.

Dahlgren, C.P. and Eggleston, D.B. (2000) Ecological processes underlying ontogenetic habitat shifts in a coral reef fish. Ecology 81, 2227-2240.

Dahlgren, C.P., Kellison, G.T., Adams, A.J., Gillanders, B.M., Kendall, M.S., Layman, C.A., Ley, J.A. et al. (2006) Marine nurseries and effective juvenile habitats: concepts and applications. Marine Ecology Progress Series 312, 291-295.

Dorenbosch, M., Verweij, M.C., Nagelkerken, I., Jiddawi, N. and van der Velde, G. (2004) Homing and daytime tidal movements of juvenile snappers (Lutjanidae) between shallow-water nursery habitats in Zanzibar, western Indian Ocean. Environmental Biology of Fishes 70, 203-209,

Dorenbosch, M., Grol, M.G.G., Nagelkerken, I. and van der Velde, G. (2005) Distribution of coral reef fishes along a coral reef-seagrass gradient: edge effects and habitat segregation. Marine Ecology Progress Series 299, 277-288.

Farmer, N.A. and Ault, J.S. (2011) Grouper and snapper movements and habitat use in Dry Tortugas, Florida. Marine Ecology Progress Series 433, 169-184.

Fodrie, F.J., Levin, L.A. and Lucas, A.J. (2009) Use of population fitness to evaluate the nursery function of juvenile habitats. Marine Ecology Progress Series 385, 39-49.

Ford, J.R., Williams, R.J., Fowler, A.M., Cox, D.R. and Suthers, I.M. (2010) Identifying critical estuarine seagrass habitat for settlement of coastally spawned fish. Marine Ecology Progress Series 408, 181-193. 
Gillanders, B.M. and Kingsford, M.J. (1996) Elements in otoliths may elucidate the contribution of estuarine recruitment to sustaining coastal reef populations of a temperate reef fish. Marine Ecology Progress Series 141, 13-20.

Gillanders, B.M., Able, K.W., Brown, J.A., Eggleston, D.B. and Sheridan, P.F. (2003) Evidence of connectivity between juvenile and adult habitats for mobile marine fauna: an important component of nurseries. Marine Ecology Progress Series 247, 281-295.

Gillanders, B.M. (2009) Tools for studying biological marine ecosystem interactions - natural and artificial tags. In: Ecological connectivity among tropical coastal ecosystems (ed I. Nagelkerken). Springer Science and Business Media, Dordrecht, pp. 457-492.

Gilliam, J.F. and Fraser, D.F. (2001) Movement in corridors: enhancement by predation threat, disturbance, and habitat structure. Ecology 82, 258-273.

Grol, M.G.G., Nagelkerken, I., Rypel, A.L. and Layman, C.A. (2011) Simple ecological trade-offs give rise to emergent cross-ecosystem distributions of a coral reef fish. Oecologia 165, 79-88.

Hammerschlag, N., Heithaus, M.R. and Serafy, J.E. (2010) Influence of predation risk and food supply on nocturnal fish foraging distributions along a mangrove-seagrass ecotone. Marine Ecology Progress Series 414, 223-235.

Helfman, G.S. (1986) Fish behavior by day, night and twilight. In: The behavior of teleost fishes (ed T.J. Pitcher). Croom-Helm, London, pp. 366-387.

Helfman, G.S., Meyer, J.L. and Mcfarland, W.M. (1982) The ontogeny of twilight migration patterns in grunts (Pisces, Haemulidae). Animal Behaviour 30, 317-326.

Hering, D.K., Bottom, D.L., Prentice, E.F., Jones, K.K. and Fleming, I.A. (2010) Tidal movements and residency of subyearling Chinook salmon (Oncorhynchus tshawytscha) in an Oregon salt marsh channel. Canadian Journal of Fisheries and Aquatic Sciences 67, 524-533.

Hitt, S., Pittman, S.J. and Nemeth, R.S. (2011) Diel movements of fishes linked to benthic seascape structure in a Caribbean coral reef ecosystem. Marine Ecology Progress Series 427, 275-291.Kneib, R.T. (2003) Bioenergetic and landscape considerations for scaling expectations of nekton production from intertidal marshes. Marine Ecology Progress Series 264, 279-296.

Igulu, M.M., Nagelkerken, I., van der Velde, G. and Mgaya, Y.D. (2013) Mangrove fish production is largely fuelled by external food sources: a stable isotope analysis of fishes at the individual, species, and community levels from across the globe. Ecosystems in press.

Kimirei, I.A., Nagelkerken, I., Mgaya, Y.D. and Huijbers, C.M. (2013a) The mangrove nursery paradigm revisited: otolith stable isotopes support nursery-to-reef movements by Indo-Pacific fishes. PLoS One 8, e66320.

Kimirei, I.A., Nagelkerken, I., Trommelen, M., Blankers, P., van Hoytema, N., Hoeijmakers, D., Huijbers, C.M., Mgaya, Y.D. and Rypel, A.L. (2013)b What drives ontogenetic niche shifts of fishes in coral reef ecosystems? Ecosystems 16, 783-796.

Kramer, D.L. and Chapman, M.R. (1999) Implications of fish home-range size and relocation for marine reserve function. Environmental Biology of Fishes 55, 65-79.

Kraus, R.T. and Secor, D.H. (2005) Application of the nursery-role hypothesis to an estuarine fish. Marine Ecology Progress Series 291, 301-305.

Krumme, U. (2009) Diel and tidal movements by fish and decapods linking tropical coastal ecosystems. In: Ecological connectivity among tropical coastal ecosystems (ed I. Nagelkerken). Springer Science and Business Media, Dordrecht, pp. 271-324.

Layman, C.A., Dahlgren, C.P., Kellison, G.T., Adams, A.J., Gillanders, B.M., Kendall, M.S., Ley, J.A. et al. (2006) Marine nurseries and effective juvenile habitats. Marine Ecology Progress Series 318, 307-308. 
Lindner, M. and Cook, H. (1970) Synopsis of biological data on the white shrimp Penaeus setiferus (Linnaeus) 1767. FAO Fisheries Reports 4, 1439-1469.

Luo, J., Serafy, J.E., Sponaugle, S., Teare, P.B. and Kieckbusch, D. (2009) Movement of gray snapper Lutjanus griseus among subtropical seagrass, mangrove, and coral reef habitats. Marine Ecology Progress Series 380, 255-269.

Manson, F.J., Loneragan, N.R., Harch, B.D., Skilleter, G.A. and Williams, L. (2005) A broadscale analysis of links between coastal fisheries production and mangrove extent: A casestudy for northeastern Australia. Fisheries Research 74, 69-85.

Minello, T.J., Matthews, G.A., Caldwell, P.A. and Rozas, L.P. (2008) Population and production estimates for decapods crustaceans in wetlands of Galveston Bay, Texas. Transactions of the American Fisheries Society 137, 129-146.

Nagelkerken, I. (2007) Are non-estuarine mangroves connected to coral reefs through fish migration? Bulletin of Marine Science 80, 595-607.

Nagelkerken, I. (2009) Evaluation of nursery function of mangroves and seagrass beds for tropical decapods and reef fishes: patterns and underlying mechanisms. In: Ecological connectivity among tropical coastal ecosystems (ed I. Nagelkerken). Springer Science and Business Media, Dordrecht, pp. 357-399.

Nagelkerken, I., Dorenbosch, M., Verberk, W.C.E.P., Cocheret de la Morinière, E. and van der Velde, G. (2000) Importance of shallow-water biotopes of a Caribbean bay for juvenile coral reef fishes: patterns in biotope association, community structure and spatial distribution. Marine Ecology Progress Series 202, 175-192.

Nagelkerken, I., Kleijnen, S., Klop, T., van den Brand, R.A.C.J., Cocheret de la Morinière, E. and van der Velde, G. (2001) Dependence of Caribbean reef fishes on mangroves and seagrass beds as nursery habitats: a comparison of fish faunas between bays with and without mangroves/seagrass beds. Marine Ecology Progress Series 214, 225-235.

Nagelkerken, I., Bothwell, J., Nemeth, R.S., Pitt, J.M. and van der Velde, G. (2008) Interlinkage between Caribbean coral reefs and seagrass beds through feeding migrations by grunts (Haemulidae) depends on habitat accessibility. Marine Ecology Progress Series 368, $155-164$.

Olds, A.D., Albert, S., Maxwell, P.S., Pitt, K.A. and Connolly, R.M. (2013) Mangrove-reef connectivity promotes the effectiveness of marine reserves across the western Pacific. Global Ecology and Biogeography 22, 1040-1049.

Pittman, S.J., Caldow, C. and Hile, S.D. (2007) Using seascape types to explain the spatial patterns of fish in the mangroves of SW Puerto Rico. Marine Ecology Progress Series 348, 273-284.

Rayfield, B., James, P.M.A., Fall, A. and Fortin, M.J. (2008) Comparing static versus dynamic protected areas in the Quebec boreal forest. Biological Conservation 141, 438449.

Rozas, L.P. and Minello, T.J. (2011) Variation in penaeid shrimp growth rates along an estuarine salinity gradient: implications for managing river diversions. Journal of Experimental Marine Biology and Ecology 397, 196-207.

Sheaves, M. (2009) The Consequences of Ecological Connectivity: the Example of the Coastal Ecosystem Mosaic. Marine Ecology Progress Series 391, 107-115.

Sheaves, M. and Johnston, R. (2008) Influence of marine and freshwater connectivity on the dynamics of subtropical estuarine wetland fish metapopulations. Marine Ecology Progress Series 357, 225-243.

Sheaves, M., Baker, R. and Johnston, R. (2006) Marine nurseries and effective juvenile habitats: an alternative view. Marine Ecology Progress Series 318, 303-306.

Simenstad, C.A., Hood, W.G., Thom, R.M., Levy, D.A. and Bottom, D.L. (2000) Landscape structure and scale constraints on restoring estuarine wetlands for Pacific Coast juvenile 
fishes. In: Concepts and controversies in tidal marsh ecology (eds M.P. Weinstein and D.A. Kreeger). Kluwer Academic Publisher, Dordrecht, pp. 597-630.

Tupper, M. (2007) Identification of nursery habitats for commercially valuable humphead wrasse Cheilinus undulatus and large groupers (Pisces: Serranidae) in Palau. Marine Ecology Progress Series 332, 189-199.

Turgeon, K., Robillard, A., Gregoire, J., Duclos, V. and Kramer, D.L. (2010) Functional connectivity from a reef fish perspective: behavioral tactics for moving in a fragmented landscape. Ecology 91, 3332-3342.

Turner, R.E. (1977) Intertidal vegetation and commercial yields of penaeid shrimp. Transactions of the American Fisheries Society 106, 411-416.

Verweij, M.C., Nagelkerken, I., Wartenbergh, S.L.J., Pen, I.R. and van der Velde, G. (2006) Caribbean mangroves and seagrass beds as daytime feeding habitats for juvenile French grunts, Haemulon flavolineatum. Marine Biology 149, 1291-1299.

Verweij, M.C., and Nagelkerken, I. (2007) Short and long-term movement and site fidelity of juvenile Haemulidae in back-reef habitats of a Caribbean embayment. Hydrobiologia 592, 257-270.

Verweij, M.C., Nagelkerken, I., Hol, K.E.M., van den Beld, A.H.J.B. and van der Velde, G. (2007) Space use of Lutjanus apodus including movement between a putative nursery and a coral reef. Bulletin of Marine Science 81, 127-138.

Verweij, M.C., Nagelkerken, I., Hans, I., Ruseler, S.M. and Mason, P.R.D. (2008) Seagrass nurseries contribute to coral reef fish populations. Limnology and Oceanography 53, 1540-1547.

Vitousek, P.M., Mooney, H.A., Lubchenco, J. and Melillo, J.M. (1997) Human domination of Earth's ecosystems. Science 277, 494-499.

Wasserman, R.J. and Strydom, N.A. (2011) The importance of estuary head waters as nursery areas for young estuary- and marine-spawned fishes in temperate South Africa. Estuarine Coastal and Shelf Science 94, 56-67.

Waycott, M., Duarte, C.M., Carruthers, T.J.B., Orth, R.J., Dennison, W.C., Olyarnik, S., Calladine, A. et al. (2009) Accelerating loss of seagrasses across the globe threatens coastal ecosystems. Proceeding of the National Academy of Sciences USA 106, 1237712381.

Weinstein, M.P. (2008) Ecological restoration and estuarine management: placing people in the coastal landscape. Journal of Applied Ecology 45, 296-304.

Whaley, S.D., Burd, J.J., Jr. and Robertson, B.A. (2007) Using estuarine landscape structure to model distribution patterns in nekton communities and in juveniles of fishery species. Marine Ecology Progress Series 330, 83-99.

Zollner, P.A. and Lima, S.L. (1999) Search strategies for landscape-level interpatch movements. Ecology 80, 1019-103 